\title{
Troid fonksiyon bozukluğu bulunan hastalarda karpal tünel sendromu: Ultrasonografik ve elektrofizyolojik değerlendirme
}

Carpal tunnel syndrome in patients with thyroid dysfunction: Ultrasonographic and electrophysiologic evaluation

\author{
Uğur $\mathrm{T}^{1} \quad$ Demirpolat $\mathrm{G}^{2} \quad$ Tuncel $\mathrm{D}^{3} \quad$ Özkaya $\mathrm{M}^{4}$ \\ ${ }^{1}$ Kahramanmaraş Sütçü İmam Üniversitesi Tıp Fakültesi, Radyoloji Anabilim Dalı, Kahramanmaraş, \\ Türkiye \\ ${ }^{2}$ Balıkesir Üniversitesi Tıp Fakültesi, Radyoloji Anabilim Dalı, Balıkesir, Türkiye \\ ${ }^{3}$ Kahramanmaraş Sütçü İmam Üniversitesi Tıp Fakültesi, Nöroloji Anabilim Dalı, Kahramanmaraş, \\ Türkiye \\ ${ }^{4}$ Kahramanmaraş Sütçü İmam Üniversitesi Tıp Fakültesi, İç Hastalıkları Anabilim Dalı, \\ Kahramanmaraş, Türkiye
}

\section{Özet}

Amaç: Tiroid fonksiyon bozukluğu bulunan hastalarda karpal tünel sendromunun (KTS), ultrasonografi (US) ve elektrofizyolojik testler ile değerlendirilmesi ve bu hastalarda KTS prevalansının araştırılması.

Gereç ve Yöntem: Tiroid fonksiyon bozukluğu (23 hipotiroidi, 17 hipertiroidi) olan 40 hastada 78 el bileği yüksek çözünürlüklü US ve elektrofizyolojik testler ile değerlendirildi. Yirmi bir sağlıklı gönüllüde 41 el bileği kontrol grubunu oluşturdu. US'de median sinirin ekojenitesi değerlendirildi ve distal radial düzey (DRD) ve proksimal karpal kemikler (psiform kemik) düzeyinde (PKD) kesitsel alanı ölçüldü. Median sinir alanının $10 \mathrm{~mm} 2$ ve üstünde olması KTS ile uyumlu olarak değerlendirildi. US ve elektrofizyolojik testler ile KTS prevalansı hesaplandı.

Bulgular: Kontrol grubunda KTS tanısı alan olgu olmadı. US'de DRD ve/veya PKD deki alan ölçümlerinden birine göre, tiroid disfonksiyonlu 6 hastada 8 el bileğine KTS tanısı koyuldu. Bu hastalarda median sinir alanı DRD'de sağda ve solda sırasıyla 11,00 ( \pm 1,82) $\mathrm{mm} 2$ ve 9,75 $( \pm 0,96) \mathrm{mm} 2$, PKD'de 13,00 ( $\pm 2,45) \mathrm{mm} 2$ ve $12,25( \pm, 63) \mathrm{mm} 2$ ölçüldü. KTS'li tüm olgularda median sinirin daha homojen ve hafif hipoekojen izlendiği dikkati çekti. KTS prevalansı US ve elektrofizyolojik testler ile sırasıyla hipotiroidide $\% 21,7$ ve $\% 17,3$; hipertiroidide $\% 5,9$ bulundu.

Sonuç: KTS'li olgularda US incelemede median sinirde ekojenite kaybı ve alan artışı saptanabilir. Hipotiroidi KTS için önemli bir risk faktörüdür. US, risk gruplarının taranmasında kullanılabilir.

Anahtar Sözcükler: Troid, karpal tünel sendromu, ultrasonografi, elektrofizyolojik test.

\section{Summary}

Aim: Our objective was to evaluate the patients with thyroid dysfunction for carpal tunnel syndrome (CTS) with ultrasonography (US) and electrophysiologic tests and to investigate the prevalance of CTS in these patients.

Materials and Methods: Seventy eight wrists in 40 patients with thyroid dysfunction (23 hypothyroid, 17 hyperthyroid) underwent US and electrodiagnostic tests. Fourty one wrists in 21 healthy volunteers constituted the control group. The echogenicity of the median nerve was evaluated and the cross-sectional area was measured at the level of distal radius (DRL) and the proximal carpal (os pisiforme) bones (PCL). A median nerve cross-sectional area over $10 \mathrm{~mm}^{2}$ was accepted as compatible with CTS. The prevalance of CTS was calculated.

Results: None of the controls were diagnosed with CTS. Eight wrists in 6 patients with thyroid dysfunction were diagnosed with CTS according to the cross-sectional area measured at DRL or PCL with US. The cross-sectional area of the median nerve at DRL on the right and left sides were $11.00( \pm 1.82) \mathrm{mm}^{2}$ and $9.75( \pm 0.96) \mathrm{mm}^{2}$ respectively. It was $13.00( \pm 2.45) \mathrm{mm}^{2}$ and $12.25( \pm 2.63) \mathrm{mm}^{2}$ at PCL. The median nerve was more homogenous and hypoechogenic in all patients with CTS. The prevalence of CTS was $21.7 \%$ and $17.3 \%$ with US and electrophysological tests respectively among hypothyroid patients and $5.9 \%$ among hyperthyroid patients.

Yazışma Adresi: Gülen DEMIRPOLAT

Balıkesir Üniversitesi Tıp Fakültesi, Radyoloji Anabilim Dalı, Balıkesir, Türkiye

Makalenin Geliş Tarihi: 30.09.2013 Kabul Tarihi: 09.12.2013 
Conclusion: Decreased echogenicity of the median nerve and higher cross sectional area can be detected with US in patients with CTS. Hypothyrodism is a prominent risk factor for CTS. US can be used for evaluating risk groups.

Key Words: Thyroid, carpal tunnel syndrome, ultrasonography, electrophysiologic testing.

\section{Giriş}

Karpal tünel sendromu (KTS) median sinirin el bileğindeki semptomatik kompresyon nöropatisidir (1). Hastaların büyük kısmında nöropatinin sebebi bulunamaz. Diğer hastalarda ise biyomekanik yüklenme, kadın olmak, gebelik, oral kontraseptif kullanımı, obezite, alkolizm, böbrek yetmezliği, diyabet, bağ dokusu hastalığı ve tiroid bezi hastalıkları gibi risk faktörleri saptanır (2-6).

Hem hipotiroidili hem de hipertiroidili hastalarda KTS tanımlanmıştır ve tiroid hormonları ile KTS arasındaki ilişki pek çok çalışmada araştırılmıştır (7-10). Bu çalışmalarda daha çok hipotiroidili hastalar değerlendirilmiş ve \%44'e varan oranlarda KTS rapor edilmiştir (11). Hipertiroidinin KTS ile ilişkisi ise çok az sayıda çalışmada değerlendirilmiştir ve hipertiroidinin KTS için bir risk faktörü olup olmadığı halen tartışmalıdır. Geçmişte tiroid fonksiyon bozukluğu bulunan hastaların tümünde KTS tanısı, hastaların yakınmalarına dayanılarak veya fizik muayene bulguları ve/veya elektrofizyolojik testlerle koyulmuştur. Pek çok araştırmacı tarafından elektrofizyolojik testler halen gold standart kabul edilse de bu testlerin yalancı pozitif ve yalancı negatif sonuçlarının olduğu bilinmektedir. Ayrıca bu testler içinde kabul görmüş tek bir yöntem yoktur ve en uygun tanısal ölçüt belirlenmemiştir $(12,13)$. Testlerin pahalı ve zaman alıcı olması da dezavantajlarındandır. Elektrofizyolojik testlerin sınırlılıkları nedeniyle KTS tanısını koyduracak veya dışlayacak yeni yöntemler önerilmiştir. Kısa sürede uygulanabilen, ağrısız ve ucuz bir yöntem olan ultrasonografinin (US) sinir ileti testlerine alternatif olabileceği düşünülmektedir $(14,15)$.

Yüksek çözünürlüklü US görüntülerinin elde edilmesine izin veren gelişmiş teknolojiye sahip transduserlerin üretilmesi ile kas iskelet sisteminin değerlendirilmesinde US'nin kullanım alanı genişlemiştir. Optimal görüntü kalitesini sağlayan yüzeyel problarla el bileği yapıları ayrıntılı şekilde görüntülenerek, KTS için tanısal kriterler belirlenmeye çalışılmıştır. US'nin KTS tanısındaki duyarlılığının ve özgüllüğünün araştırıldığı yayınlar içinde US'nin elektrofizyolojik testlerin yerini alamayacağını bildiren çalışmalar olduğu gibi, tanıda ilk inceleme yöntemi olarak kullanılabileceğini gösteren yayınlar da vardır (16-18).

$\mathrm{Bu}$ çalışmada, tiroid fonksiyon bozukluğu bulunan hastalarda ve kontrol grubunda karpal tünel yapıları US ile değerlendirildi. Tüm olgular halen gold standart yöntem kabul edilen elektrofizyolojik testlerle de incelendi ve sinir ileti testleri ile KTS tanısı koyulan hastaların US bulguları kontrol grubu ile kıyaslandı. Her iki yöntemle hipotiroidili ve hipertiroidili hastalardaki KTS prevalansı hesaplandı.

\section{Gereç ve Yöntem}

Bu prospektif çalışmada etik kurul kararı alınmış, olgular işlem öncesinde bilgilendirilmiş ve işlemler için onayları alınmıştır.

Hastalar ayrıntılı anamnez alınarak değerlendirilmiş ve öyküsünde KTS gelişiminde bilinen risk faktörleri olan romatoid artrit, gut, diyabet, obezite, hamilelik, kronik böbrek yetmezliği ve amiloidoz olan, oral kontraseptif ve diüretik kullanımı bulunan olgular çalışmaya dâhil edilmemiştir. Çalışmamızda tiroid fonksiyon bozukluğu (12 hipotiroidili ve 11 subklinik hipotiroidili olmak üzere toplam 23 hipotiroidili hasta ve 6 hipertiroidili, 11 subklinik hipertiroidili olmak üzere toplam,17 hipertiroidili hasta) olan 40 yetişkin olguda (ortalama yaş 41 ; dört erkek, 36 kadın) toplam 78 el bileği US ve elektrofizyolojik testler ile değerlendirildi. Çalışma grubu ile benzer yaşlarda olan (ortalama yaş 39,9; üç erkek, 18 kadın) toplam 21 sağlıklı gönüllüde de 41 el bileği kontrol grubu olarak incelendi. Bir hastada el bileğinde kırık öyküsü bulunduğundan sol el bileği çalışma dışında bırakıldı. Biri hasta, diğeri kontrol grubunda olmak üzere iki el bileğinde US incelemede bifid median sinir gözlendi ve bu el bilekleri de çalışma dışında tutuldu.

\section{Ultrasonografik Değerlendirme}

US inceleme elektromyografi (EMG) testini takip eden 1 haftada içinde ve hastaların klinik, laboratuar ve elektrofizyolojik testlerinin sonuçlarını bilmeyen 2 radyolog tarafından yapıldı. İncelemede Toshiba Aplio cihaz (SSA-7700A brand XU) ve 7-14 MHz multifrekans lineer problar kullanıldı. İncelemede artefaktları azaltan ve çözünürlüğü arttıran doku harmonik görüntüleme (tissue harmonic imaging) tekniği kullanıldı.

Karpal tünel, hasta inceleyicinin karşısında otururken, avuçları yukarıda (supinasyonda) ve parmaklar açıkken transvers ve longitudinal planda değerlendirildi. Median kanaldaki tendonlar, kaslar ve kan damarları ile birlikte median sinirin ekojenitesi incelendi. Median sinirin distal radial düzey (DRD) ve proksimal karpal kemikler düzeyinde (PKD) (psiform kemik düzeyi) kesitsel alanları aksiyal planda ölçüldü. Median sinire bası oluşturmadan her seviyeden 3'er ölçüm yapıldı. Aritmetik ortalama değerleri hesaplandı ve bu değer geçerli değer olarak kabul edildi. Her iki el bileğinin değerlendirilmesi ortalama 15 dakikada tamamlandı. Önceki araştırmalara dayanılarak median sinir alanının $10 \mathrm{~mm}^{2}$ ve üstünde 
olması KTS ile uyumlu olarak değerlendirildi. Median sinirde normalde izlenen benekli görünümün kaybı tanıyı destekleyici bulgu olarak kabul edildi.

\section{Elektrofizyolojik Değerlendirme}

$\mathrm{Bu}$ değerlendirmede tüm hastalara; KTS tansı için, her iki elde median ve karşılaştırmak için sağ ulnar sinirde duyu ve motor iletim çalışmaları yapıldı. Kayıtlamalar için yüzeyel elektrotlar kullanıldı. Tetkiki yapan nöroloğun hasta ve kontrol grubu hakkında bilgisi yoktu.

\section{Istatiksek Analiz}

$\mathrm{Bu}$ çalışmada istatistiksel analizler SPSS (Statistical Package for Social Sciences) 15.0 programı kullanılarak yapıldı. Parametrik verilerin gruplar arası değerlendirilmesinde One-Way ANOVA testi, grup içi değerlendirmede ise Mann-Whitney $U$ testi kullanıldı. Nonparametrik testler için $x^{2}$ testi uygulandı. Sonuçlarda anlamlılık $p=0.05$ düzeyinde değerlendirildi.

\section{Bulgular}

Kontrol grubunda US de median sinirde ekojenite azalması ve DRD ve PKD arasında anlamlı kesitsel alan değişiklikleri saptanmadı ve KTS tanısı alan vaka olmadı. Kontrol grubunda median sinirin aksiyal planda alanı DRD'de sağda $7.70( \pm 1.75)$, solda $7.95( \pm 1.71)$ $\mathrm{mm}^{2}$, PKD'de sağda $8.00( \pm 0.97)$, solda $7.67( \pm 1.11)$ $\mathrm{mm}^{2}$ ölçüldü (Şekil-1). Elektrofizyolojik testler ile US bulguları tamamıla uyumluydu.

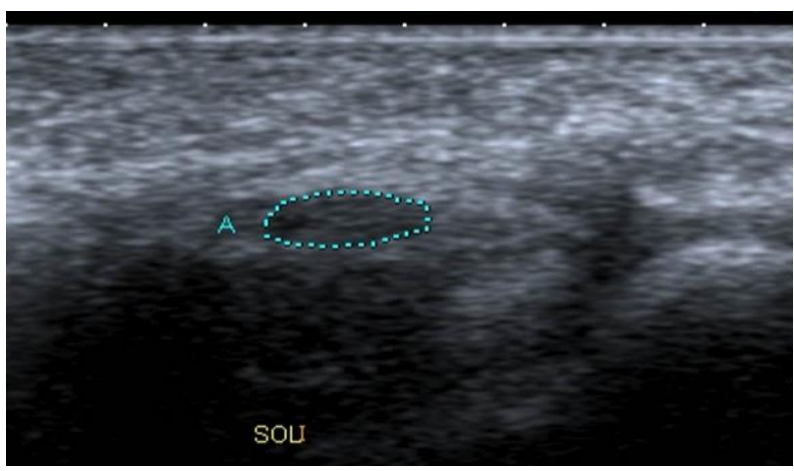

Şekil-1. Aksiyal planda US kesitinde kontrol grubunda proksima karpal kemikler düzeyinde median sinir alanı $6 \mathrm{~mm}^{2}$ ölçülmüştür.

Hasta grubunda DRD'de ve/veya PKD'de yapılan alan ölçümlerinden birine göre 6 hastada 8 el bileğine KTS tanısı koyuldu. Kontrol grubu ile karşılaştırıldığında her iki el bileğinde DRD ve PKD'de istatistiksel olarak anlamlı alan artışı saptandı $(p=0,05)$. Median sinir alanındaki artışın PKD'de daha belirgin olduğu görüldü. KTS'li tüm olgularda median sinirin daha homojen ve hafif hipoekojen izlendiği dikkati çekti. Bu olgularda median sinir alanı DRD'de sağda $11.00( \pm 1.82) \mathrm{mm}^{2}$, solda $9.75( \pm 0.96) \mathrm{mm}^{2}$. PKD'de sağda $13.00( \pm 2.45)$ $\mathrm{mm}^{2}$ solda 12.25 ( \pm 2.63$) \mathrm{mm}^{2}$ ölçüldü (Şekil-2).

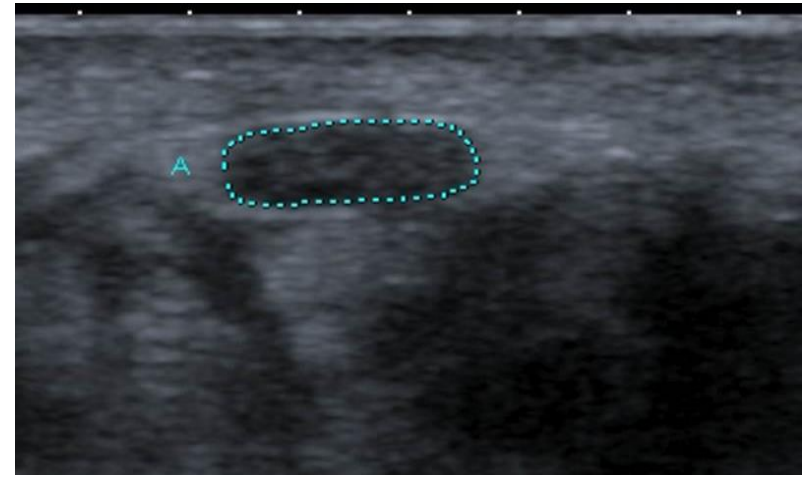

Şekil-2. KTS'li olguda aksiyal planda US görüntüsünde; sağ el bileğinde proksimal karpal kemikler düzeyinde median sinir alanının belirgin şekilde genişlemiş olduğu

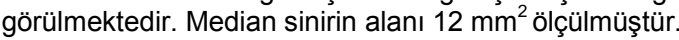

US ile KTS tanısı koyulan olgulardan 5'i hipotiroidili (2 hastada bilateral), 1'i hipertiroidili hastalardı. Hipotiroidili hastalarda median sinirin alanı ortalama DRD'de $10,5 \mathrm{~mm}^{2}$, PKD'de $13 \mathrm{~mm}^{2}$, hipertroidili tek olguda DRD'de $9 \mathrm{~mm}^{2}$, PKD'de $10 \mathrm{~mm}^{2}$ ölçüldü. US ile KTS tanısı alan hipotiroidili ve hipertiroidili hastaların sonuçları tabloda gösterilmiştir. US ile hipotiroidili hastalarda KTS prevalansı \%21,7, hipertiroidili hastalarda \% 5,9 bulundu.

Elektrofizyolojik testler ile 5 hastaya KTS tanısı koyuldu. $\mathrm{Bu}$ hastaların 4'ü hipotiroidili $(17,3 \%)$, 1'i hipertiroidili hastalardı (5,9\%).

Bir hastada sağ el bileğinde US ile KTS tespit edildi, elektrofizyolojik testler ise normaldi. Bu olgunun sağda daha fazla olmak üzere her iki el bileğinde de şikâyetleri vardı. Başka bir olguda ise sinir iletim çalışmaları ile her iki el bileğine KTS tanısı koyuldu, ancak US de sadece sağ el bileğinde KTS bulguları izlendi. Bu hasta her iki elinde aynı derecede uyuşma tanımlıyordu.

\section{Tartışma}

KTS, karpal kemikler ve transvers karpal ligamanın sınırladığı karpal tünel içinde median sinirin sıkışması ile oluşan tuzak nöropatisidir. Tüm tuzak nöropatilerinin $\% 90$ 'nı oluşturur (1). Genel popülasyonda prevalansının erkeklerde \%0,6, kadınlarda \%5,8 olduğu tahmin edilmektedir (19). KTS' nin en yaygın belirtileri median sinirin distal dağılım alanlarında (başparmak mediali, işaret, orta parmak ve yüzük parmağının lateral kesimi) uyuşma, ağrı, yanma ve karıncalanma gibi duysal yakınmalardır (1). Motor tutulum ince el hareketlerini yapmada beceriksizlik, sakarlık ve kuvvet kaybı şeklinde belirti verebilir. Ancak tenar kaslarda atrofi gelişene kadar hastalık saptanamayabilir.

KTS'de idiopatik olguların dışında pek çok risk faktörü tanımlanmıştır. Tiroid bezi hastalıkları da KTS'li hastalarda genel popülasyondan daha sık saptanan önemli risk faktörlerindendir. Troid fonksiyon bozukluğu bulunan hastalarda en sık saptanan nöromuskuler rahatsızlığın 
KTS olduğu bildirilmiştir (20). Hipotiroidinin sebep olduğu aksonal hasarın ve/veya demyelinizasyonun nöropatinin sebebi olabileceği öne sürülmüştür $(21,22)$. Hipertiroidide ise nöropati daha seyrek ve genellikle subkliniktir (23). Tirotoksik hastalarda kilo kaybının, güçsüzlüğün, tendon kılıfının mukopolisakkaritlerle infiltrasyonunun, infiltratif dermopatinin ve tiroid hormonlarının aksonal fonksiyona direkt etkilerinin mononöropati gelişmesine katkıda bulunabileceği düşünülmektedir $(22,24)$.

Troid fonksiyon bozukluğu olan hastalarda KTS prevalansı farklı araştırmalarda klinik bulgular, fizik muayene ve elektrodiyagnostik testler ile araştırılmıştır. Sinir ileti testlerinin KTS tanısındaki duyarlılığı \% 29-100, özgüllüğü \%80-99'dur $(1,12,25,26)$. Bu testler çoğu zaman gold standart kabul edilse de yanlış pozitif/yanlış negatif sonuçları vardır ve bariz klinik bulguları olan KTS'li olguların \%16-34'nde negatif sonuç verirler $(1,27)$. KTS tanısında US'nin sinir ileti testlerine alternatif olup olamayacağı halen araştırılmaktadır.

Bileşik (compound) görüntüleme ve doku harmonik görüntüleme gibi artefaktları azaltarak kenar keskinliğini, uzaysal ve kontrast çözünürlüğü arttıran cihazların günlük kullanıma girmesiyle tüm kas iskelet sisteminin değerlendirilmesinde olduğu gibi KTS tanısında da US daha çok kullanılmaya başlamıştır. US'nin KTS tanısındaki duyarlılığı \%82-94, özgüllüğü \%65-97'dir (27-29). Santral frekans aralığı 7-10 MHz olan yüzeyel problar ile median sinirde intranöral ödeme bağlı ekojenite kaybı, os hamatumun çengeli seviyesinde yassılaşma, psiform kemik seviyesinde kalınlaşma, PKD'de DRD'e oranla daha belirgin şişme ve fleksor retinakulumda palmar yaylanma gibi bulgular tanımlanmıştır (17,18,27-30). Çok sayıda çalışmada PKD'de median sinirde alan artışı en çok saptanan bulgu olmuştur (30). Median sinir alanının $9-11 \mathrm{~mm}^{2}$ olması KTS tanısında kritik değer olarak gösterilmiştir $(29,30)$. Bizim çalışmamızda da median sinirde DRD'de ve PKD'de kontrol grubu ile kıyaslandığında anlamlı alan artışı saptanmış, ayrıca PKD'deki alan artışının DRD'deki alan artışından daha fazla olduğu bulunmuştur. Sonuçlarımız literatür bulguları ile uyumludur.

Bizim çalışmamızda US ile hipotiroidili hastaların \% 21,7'sinde, EMG ile \%17,39'unda KTS saptanmıştır. $\mathrm{Bu}$ oran önceki çalışmalarda bildirilen oranlardan daha düşüktür. Tiroid hastalığı dışında KTS'ye sebep olabilecek risk faktörleri bulunan hastaların çalışmaya katılmaması bulunan oranı düşürmüş olabilir. Hipotiroidili hastalarda klinik muayene ve sinir ileti çalışmaları ile KTS sıklığı \%23-44 gibi çok değişen oranlarda bildirilmiştir $(5,7,21,31)$. Bu çalışmalarda sinir ileti testlerinde farklı yöntemler kullanılmıştır. Ayrıca bazı çalışmalarda hangi ölçütün pozitif kabul edildiği de belli değildir. Kullanılan yöntemlerin ve tanı kriterlerinin standart olmamasının prevalans hesaplarını değiştirebileceğini düşünüyoruz.

Hipotiroidili hastalarda tanısal ölçütlerdeki farklılıklar dışında prevalansı etkileyebilecek başka faktörler de vardır. Tedavi almamış spontan klinik hipotiroidisi olan 40 hasta ile 40 sağlıklı olgunun elektromyografi ve sinir ileti testleri ile değerlendirildiği bir çalışmada hastaların $\% 32,5$ 'nde (13 hasta) KTS saptanmıştır. Bu çalışmada cinsiyetin, ileri yaşın ve hipotroidi süresinin KTS ile ilişkili olduğu bulunmuştur (31). Keçeci ve arkadaşlarının 40 hipotiroidili olguyu elektrofizyolojik testlerle değerlendirdiği çalışmada, hormon replasman tedavisi verilmeden önce hastaların \%37,5'unda, tedaviden sonra ise sadece \%5'nde KTS saptanmıştır (21). Aynı şekilde, miksödem olgularında da homon replasman tedavisi ile KTS bulgularının kaybolduğunu bildiren yayınlar vardır (8). Cerrahi tedavi uygulanan 627 hastanın kayıtlarının değerlendirildiği retrospektif çalışmada diyabet, tiroid hastalığı, inflamatuar artrit, hemodiyaliz, hamilelik, kortikosteroid tedavisi ve östrojen replasman tedavisi ile KTS arasındaki ilişki araştırılmıştır. Çalışmanın sonucunda hipotiroidinin cerrahi tedavi gerektiren KTS riskini $\% 70$ oranında arttırdığı, hormon replasman tedavisinin ise bu riski etkilemediği saptanmıştır. Aynı çalışmada hipertiroidi ile KTS arasında ise ilişki bulunmamıştır (6). Çakır ve arkadaşlarının çalışmasında 23 hipotiroidili hastanın 7'sinde KTS saptanırken, 10 subklinik hipotiroidili hastanın hiçbirinde KTS bulunmamıştır (22). Yirmiyedi subklinik hipotiroidili olgunun periferal nöropati yönünden elektrofizyolojik testlerle değerlendirildiği bir çalışmada KTS tanısı alan vaka olmamıştır (32). Bizim çalışmamızda US ile KTS tanısı koyulan hipotiroidili hastaların 3'ü hipotiroidili, 2'si ise subklinik hipotiroidili vakalardı. Elektrofizyolojik testlerle 1 hipotiroidili hasta daha KTS tanısı almıştı. Bu çalışmaların sonuçları hipotiroidinin, subklinik olup, olmamasının, hipotiroidi süresinin ve hastaların hormon replasman tedavisi alıp almamasının da KTS prevalansını etkileyebileceğini göstermektedir. Sunulan araştırmada tiroid hastalığı bulunan olguların hormon replasman tedavisi ve hastalığın süresi açısından sorgulanmaması çalışmanın sınırlılıklarındandır.

Hipertiroidili hastalarda KTS prevalansının araştıııldığı sadece birkaç çalışma vardır. Çakır ve arkadaşlarının Tinnel ve Phalen testi pozitif olan tirotoksikozlu olgularda (42 hasta) sinir ileti testleri ile KTS prevalansını \%7,1 bulmuştur (22). Çalışmalarında subklinik tirotoksikoz saptanan 23 hastanın hiçbirinde KTS tespit edilmemiştir. Bizim çalışmamızda KTS tanısı alan olgu subklinik hipertiroidiliydi. Başka bir çalışmada 2 yıl takip edilen 60 tiroitoksikozlu olguda KTS sıklığı klinik ve nörofizyolojik değerlendirme ile $\% 5$ bulunmuş ve KTS bulgularının tiroid hormon dengesi ile paralel seyrettiği bildirilmiştir (24). Çalışmamızda 17 hipertiroidili hastanın 1'nde 
(\% 5.9) US ve EMG ile KTS tanısı koyulmuştur. Bu oran genel popülasyondaki KTS oranından fazla değildir. Ancak hipertiroidili hasta sayısının az oluşu çalışmamızın sınırılıklarındandır.

Çalışmamızda 2 olguda US ve EMG bulguları uyumsuz bulunmuştu. Semptomatik iki el bileğinden birinde sadece US ile diğerinde ise sadece EMG ile KTS tanısı koyulmuştu. Bu durum elektrofizyolojik testlerin sınırlılıklarına, etkilenmemiş sinir fibrillerinin varlığına veya KTS'i taklit edebilen hastalıklara bağlı olabilir. US'si normal olan ancak klinik bulguları pozitif olan hastalarda elektrofizyolojik testlerin yapılması önerilmektedir. US ile elektrofizyolojik testlerin birbirini tamamlayıcı yöntemler olarak kullanılabileceği düşünülmektedir $(1,15,28)$. US'nin tedavi seçimini ve tedavinin başarısını etkileyen anatomik varyasyonları (persistan median arter, bifid median sinir), karpal tüneldeki yer kaplayıcı lezyonları (hemanjiom, ganglion, lipom) ve lokal inflamatuar durumları gösterebilmesi avantajlarındandır. Sunulan çalışmamızda da 2 hastada bifid median sinir tespit edilmişti.

\section{Sonuç}

KTS'de, US ile median sinirde ekojenite kaybı ve PKD'de alan artışı saptanabilir. Hipotiroidi KTS için önemli bir risk faktörüdür. KTS risk gruplarının araştırılmasında US kolay uygulanabilen, ucuz ve doğruluğu yüksek bir tanısal yöntem olarak kullanılabilir.

\section{Kaynaklar}

1. Ibrahim I, Khan WS, Goddard N, Smitham P. Carpal tunnel syndrome: A review of the recent literature. Open Orthop J 2012;6:69-76.

2. Ferry $S$, Hannaford $P$, Warskyj $M$, Lewis $M$, Croft $P$. Carpal tunnel syndrome: A nested case control study of risk factors in women. Am J Epidemiol 2000; 151(6):566-74.

3. Nathan PA, Meadows KD, Istvan JA. Predictors of carpal tunnel syndrome: An 11 year study of industrial workers. J Hand Surg 2002;27(4):644-51.

4. Bril V, Perkins BA. Carpal tunnel syndrome in patients with diabetic polyneuropathy. J Peripher Nerv Syst 2000;5(3):180.

5. Palumbo CF, Szabo RM, Olmsted SL. The effects of hypothyroidism and thyroid replacement on the development of carpal tunnel syndrome. J Hand Surg Am 2000;25(4):734-9.

6. Solomon DH, Katz JN, Bohn R, Mogun H, Avorn J. Nonoccupational risk factors for carpal tunnel syndrome. J Gen Intern Med 1999;14(5):310-4.

7. Duyff RF, Van den Bosch J, Laman DM, Van Loon BJ, Linssen WH. Neuromuscular findings in thyroid dysfunction: A prospective clinical and electrodiagnostic study. J Neurol Neurosurg Psychiatry 2000;68(6):750-5.

8. Frymoyer JW, Bland J. Carpal tunnel sendrome in patients with myxedematous arthropaty. J Bone Joint Surg Am 1973;55(1):78-82.

9. Beard L, Kumar A, Estep HL. Bilateral carpal tunnel syndrome caused by Grave's disease. Arch Intern Med 1985;145(2):345-6.

10. ljichi S, Niina K, Tara M, et al. Mononeuropathy associated with hyperthyroidism. J Neurol Neurosurg Psych 1990;53 (12):110910.

11. Cruz MW, Tendrich M, Vaisman M, Novis SA. Electromyography and neuromuscular findings in 16 primary hypothyroidism patients. Arq Neuro-Psiquiat 1996;54(1):8-12.

12. Atroshi I, Gummesson C, Johnsson R, Ornstein E. Diagnostic properties of nerve conduction tests in population-based carpal tunnel syndrome. BMC Musculo Skelet Disord 2003;4:1-7.

13. Werner RA, Andary M Electrodiagnostic evaluation of carpal tunnel syndrome. Muscle Nerve 2011;44(4):597-607.

14. Mhoon JT, Juel VC, Hobson-Webb LD. Median nerve ultrasound as a screening tool in carpal tunnel syndrome: Correlation of cross-sectional area measures with electrodiagnostic abnormality. Muscle Nerve 2012;46(6):871-8.

15. Ziswiler HR, Reichenbach S, Vögelin E, Bachmann LM, Villiger PM, Jüni P. Diagnostic value of sonography in patients with suspected carpal tunnel syndrome: A prospective study. Arthritis Rheum 2005;52(1):304-11.

16. Claes F, Kasius KM, Meulstee J, Verhagen WI. Comparing a new ultrasound approach with electrodiagnostic studies to confirm clinically defined carpal tunnel syndrome: a prospective, blinded study. Am J Phys Med Rehabil 2013;92(11):1005-11.

17. El Miedany YM, Aty SA, Ashour S. Ultrasonography versus nerve conduction study in patients with carpal tunnel syndrome: Substantive or complementary tests? Rheumatology (Oxford) 2004;43(7):887-95.

18. Karadağ YS, Karadağ O, Ciçekli $E$ et al. Severity of Carpal tunnel syndrome assessed with high frequency ultrasonography. Rheumatol Int 2010;30(6):761-5.

19. de Krom MC, Knipschild PG, Kester AD, Thijs CT, Boekkooi PF, Spaans F. Carpal tunnel syndrome. J Clin Epidemiol 1992;45(4):373-6.

20. El-Salem K, Ammari F. Neurophysiological changes in neurologically asymptomatic hypothyroid patients: A prospective cohort study. J Clin Neurophysiol 2006;23(6):568-72.

21. Kececi H, Degirmenci Y. Hormone replacement therapy in hypothyroidism and nerve conduction study. Neurophysiol Clin 2006;36(2):79-83.

22. Çakır M, Samancı N, Balcı N, Balcı MK. Musculoskeletal manifestations in patients with thyroid disease Clin Endocrinol 2003;59(2):162-7.

23. Kumar N, Gadpayle AK, Roshan S. Thyrotoxic myo-neuropathy. J Indian Acad Clin Med 2012;13(3):255-6.

24. Roquer J, Cano JF. Mononeuropathies in thyrotoxicosis. J Neurol Neurosurg Psychiatry 1992;55(4):332. 
25. Jablecki CK, Andary MT, Floeter MK, et al. Practice parameter: electrodiagnostic studies in carpal tunnel syndrome. Report of the American Association of Electrodiagnostic Medicine, American Academy of Neurology, and the American Academy of Physical Medicine and Rehabilitation. Neurology 2002;11(58):1589-92.

26. Nakamichi K, Tachibana S. Ultrasonographic measurement of median nerve cross-sectional area in idiopathic carpal tunnel syndrome: Diagnostic accuracy. Muscle Nerve 2002;26(6):798-803.

27. Duncan I, Sullivan P, Lomas F. Sonography in the diagnosis of carpal tunnel syndrome. AJR Am J Roentgenol 1999;173(3):681-4.

28. Wong SM, Griffith JF, Hui ACF, Tang A, Wong KS. Discrimantory sonografic criteria for the diagnosis of carpal tunnel syndrome. Arthritis Rheum 2002;46(7):1914-21.

29. Sernik RA, Abicalaf CA, Pimental BF, Baiak AB, Braga L, Cerri GG. Ultrasound features of carpal tunnel syndrome: $A$ prospective case-control study. Skeletal Radiol 2008;37(1):49-53.

30. Beekman R, Visser LH. Sonography in the diagnosis of carpal tunnel syndrome: A critical rewiew of the literature. Muscle Nerve 2003;27(1):26-33.

31. Eslamian F, Bahrami A, Aghamohammadzadeh N, Niafar M, Salekzamani Y, Behkamrad K. Electrophysiologic changes in patients with untreated primary hypothyroidism. J Clin Neurophysiol 2011;28(3):323-8.

32. Misiunas A, Niepomniszcze H, Ravera B, Faraj G, Faure E. Peripheral neuropathy in subclinical hypothyroidism. Thyroid 1995;5(4):283-6. 